\title{
Motivators and barriers to vaccination of health professionals against seasonal influenza in primary healthcare
}

\author{
Davorina Petek ${ }^{* *}$ and Kristina Kamnik-Jug ${ }^{2}$
}

\begin{abstract}
Background: Over the last decade, the vaccination rates amongst the general population in Slovenia were declining. According to the World Health Organisation, the vaccination rates amongst healthcare workers are also low throughout Europe. The aim of this study was to evaluate vaccination rates for seasonal flu amongst healthcare workers on the primary care level in the Koroška region and to find motivators and barriers for vaccination.

Methods: In a cross-sectional study, an anonymous questionnaire was distributed to all health centres, nursing homes and private contractors, who agreed to participate. Out of 334 distributed questionnaires, 250 (74.8\%) were analysed. Bivariate and multivariable statistical analyses were conducted.

Results: Only 12\% of included health professionals were vaccinated in the 2014/15 season. The main motivators for vaccination coverage were: awareness of high risk of infection at the workplace, self-protection and protection of family members and co-workers. The main barriers for vaccination were doubt in the effectiveness of the vaccine, fear of side effects and the belief that health professionals are not at high risk of influenza infection. In the multivariable model, a positive association was found between the vaccination, older age and belief in the effectiveness against influenza, while a negative association was found between the nurses' profession and vaccination.

Conclusion: The trend of declining rates for seasonal influenza vaccination is continuing. Protection of the patients was not among the most important reasons for vaccination. This especially endangers clients of nursing homes. The recognized motivators, barriers and other factors that were important for vaccination coverage/hesitancy could be used for designing strategies and educational programmes for health professionals to improve the vaccination coverage rates. The strategy should include the specifics of health profession groups.
\end{abstract}

Keywords: Influenza vaccination, Healthcare worker, Primary care, Risk groups

\section{Background}

Influenza is an acute respiratory tract infection caused by influenza viruses. Seasonal influenza causes an overload of medical services on all levels of medical care and a high influx of patients admitted into hospital. In addition to over-burdened hospitals, these outbreaks also cause major healthcare system disorders, due to a lack of medical staff that suffer from influenza during these outbreaks $[1,2]$.

\footnotetext{
*Correspondence: davorina.petek@gmail.com

'Department of Family Medicine, Faculty of Medicine, University of Ljubljana, Poljanski nasip 58, 1000 Ljubljana, Slovenia

Full list of author information is available at the end of the article
}

Vaccination is the most important public health measure for the prevention of seasonal and pandemic flu. Vaccination aims to reduce the population's illness rate, the number of patients treated in hospitals and the mortality rate due to influenza complications. Vaccination of health professionals is also a way of maintaining full functionality of the healthcare system and protecting the patients during an epidemic or pandemic [1].

Health professionals are highly exposed to influenza in their workplace and can transmit the infection onto others. The World Health Organization (WHO) therefore classifies health professionals into the group of people for whom vaccination against influenza is recommended [3]. According to studies, approx. $20 \%$ of health

(C) The Author(s). 2018 Open Access This article is distributed under the terms of the Creative Commons Attribution 4.0 International License (http://creativecommons.org/licenses/by/4.0/), which permits unrestricted use, distribution, and 
professionals test positive for serologically confirmed influenza viruses during an epidemic. Infections are often asymptomatic, or - in $50 \%$ of the cases - subclinical. These individuals represent the potential source of infection at their workplace for patients and their co-workers [4].

Vaccination has been shown to reduce the number of serologically confirmed infections [1]. In view of this, vaccination is recommended as a preventive measure for self-protection and, consequently, an indirect protection of patients, co-workers, family members and others [4]. Preventing the infection of health professionals is also extremely important for the undisturbed functioning of the system, especially in case of major influenza outbreaks [5].

The evidence that vaccination of health professionals is effective for the protection of patients against influenza and influenza-like infections is relatively scarce $[4,6]$. Some studies report a reduced mortality rate, fewer consultations with the family physician and fewer hospitalizations for nursing home residents at the time of an outbreak, if the staff had been vaccinated [3, 7].

The WHO and the National Institute of Public Health in Slovenia (NIJZ) encourage and promote vaccination of health professionals. Nevertheless, the vaccination coverage amongst Slovenian health professionals remains very low. Furthermore, there is a lack of records on the vaccination of employees in healthcare organizations [8].

Numerous studies that have examined health professionals' views on vaccination have divided reasons for rejecting the vaccine into two major groups. The first group is the misrepresentation and misconception of influenza and its risks, the role of health professionals and the possibility that they infect their patients, and also the importance of vaccination, its effectiveness and safety. The second major group is a lack of easy access to free vaccine [9-12].

The law in Slovenia dictates the vaccination of health professionals who can be exposed to biological agents at their workplace or who can infect other people. Vaccination-related issues are controlled by the 'Directive on the protection of workers from risk related to exposure to biological agents at work'. This Directive provides that employers must, according to their national law, offer their employees free vaccination on the basis of a risk assessment of exposure to biological agents against an effective vaccine [13, 14]. It follows that employers should cover the cost of influenza vaccinations and offer it to their employees free of charge, but the vaccination against influenza is not obligatory for health-workers.

Some of the healthcare organizations in other countries have decided to mandate the vaccination of health professionals against seasonal influenza [15]. Studies have confirmed that mandatory vaccination, where sanctions for non-compliance are not envisaged, does not have the same impact $[8,15]$. Mandatory vaccinations for health professionals could be very effective, but at the same time they raise a number of issues on the freedom of choice. In comparison to mandatory vaccinations, the recommendation to get vaccinated is the milder approach towards achieving higher levels of vaccination coverage [8].

The aim of this study was to evaluate vaccination rates for seasonal flu amongst health professionals at the primary care level in Slovenia and to find motivators and barriers for the vaccination.

\section{Methods}

\section{Sampling}

In the cross-sectional study below, the data for analysis was gathered with an anonymous questionnaire for the 2014/15 vaccination season, from April to June 2015.

We invited all major healthcare providers in primary care in the region, among them primary healthcare centres with associated emergency services, nursing homes and private contractors. The list of health professionals was obtained via the National Institute for Public Health's (NIJZ) freely accessible database of primary health professionals and covered the following positions: physicians, dentists, practice and registered nurses, community nurses, paramedics, nurse-carers, physiotherapists and occupational therapists.

The vaccination rate in 2014/15 was compared to the rate in 2013/14. We calculated the number of the vaccinated health workers in 2013/2014 from the database of the NIJZ (the number of all health workers [16] in the region and the number of vaccinated health workers in the region in 2013/14 [17].

\section{Questionnaire}

The anonymous questionnaire made up of 27 questions and divided into 5 sections was designed based on both the review of specialised literature and the overall aim of the study. We have designed the questions on the basis of domestic and international literature [9-12] and national "grey" literature - specialist thesis that also involved qualitative research (semistructured interviews) with chronic patients and their attitudes towards vaccination against flu. The sections covered the demographic data of the participants, questions about health characteristics, knowledge and beliefs of influenza vaccination, and the reasons pro or against being vaccinated (multiple choice questions).

\section{Variables}

The outcome variable was vaccination against influenza in the season 2014/15. Several explanatory variables 
about potential reasons for and against vaccination were tested for associations with the vaccination. The multivariable logistic regression model included demographic characteristics (gender, age over 50 years, occupation of health professional), health characteristic (self reported presence of chronic disease), free vaccination availability, being well informed about the influenza (self assessed knowledge), beliefs about exposure at the work place, safety and effectiveness of the vaccine..

\section{Data analysis}

The data was processed with the IBM SPSS 22 (IBM Corp., Armonk, NY) software. The statistical analysis included descriptive statistics, which was presented by frequencies and percentages or by mean values \pm standard deviations. Binary logistic regression using the standard entry method was apllied to determine the associations between the explanatory variables discussed and influenza vaccination. Crude and adjusted odds ratios with $95 \%$ confidence intervals were calculated. The explanatory variables included in the multivariable regression model were adjusted among each other. The explanatory variables included in the multivariable regression model were also tested for multicollinearity using variance inflation factor (VIF) $\left[\mathrm{VIF}=1 /\left(1-\mathrm{R}^{2}\right)\right.$ ]. $\mathrm{R}^{2}$ (Nagelkerke $\mathrm{R}^{2}$ for logistic regression) was obtained by regressing each explanatory variable on the remaining explanatory variables in the model. Statistical significance was set at $p<0.05$.

\section{Results}

\section{Sample description}

Four hundred and eighty nine primary health professionals from the national list of healthcare professionals in the Koroška region were invited to participate in the study. Three hundred and thirty four healthcare professionals agreed to participate. The questionnaire, delivered in paper form, was completed by 263 health professionals (53.7\%), while 13 were excluded from the analysis due to incomplete data. The final sample size therefore amounted to 250 health professionals $(51.1 \%$ of the eligible sample and $74.8 \%$ of the distributed questionnaires). The basic characteristics of participants are listed in Table 1.

The mean age of health professionals was $41.5 \pm 12.2$ in the range of 19 to 74 years. Among physicians, family and general practitioners were dominant (37 out of 44 or $84.1 \%) ; 10$ out of 37 general practitioners (27.0\%) were vaccinated.

In the 2014/15 vaccination season, 30 people or $12.0 \%$ of health professionals in our sample were vaccinated which is $5 \%$ less than the year before. As the data on vaccination of primary care workers was not available, we could compare the vaccination rate in 2013/14 of all health workers in the region from the national database
Table 1 A description of the sample of participating health professionals

\begin{tabular}{lll}
\hline $\begin{array}{l}\text { Health professionals/ } \\
\text { institutions }\end{array}$ & $\begin{array}{l}\text { Included } \\
n=250(\%)\end{array}$ & $N$ (number of vaccinated) \% \\
\hline Sex & $62(24.8)$ & $8(12.9)$ \\
Male & $188(75.5)$ & $22(11.7)$ \\
Female & & \\
Occupation & $44(17.6)$ & $13(29.5)$ \\
Physician & $129(51.6)$ & $12(9.3)$ \\
Nurses & $17(6.8)$ & $0(0)$ \\
Paramedic & $14(5.6)$ & $4(28.6)$ \\
Dentist & $46(18.4)$ & $1(2.2)$ \\
Other health professionals & & \\
Type of healthcare institution & & $23(18.5)$ \\
Health centre & $124(49.6)$ & $2(2.4)$ \\
Nursing home & $81(32.4)$ & $5(23.8)$ \\
Private contractor & $21(8.4)$ & $0(0)$ \\
Emergency centre & $24(9.6)$ &
\end{tabular}

of vaccination. Out of 1113 health workers, 192 people or $17.3 \%$ of health professionals were vaccinated in the 2013/14 vaccination season [17]. The difference was statistically significant $\left(\mathrm{chi}^{2}=4.121 ; p=0.042\right)$.

The reasons for vaccination are shown in Table 2. The two most important reasons for vaccination, expressed by health professionals, were belonging to a risk occupational group $(83.3 \%)$ and self-protection against influenza $(70.0 \%)$.

In the $2014 / 15$ season, $220(88.0 \%)$ health professionals did not vaccinate against seasonal influenza. The reasons for the decision against vaccination are presented in Table 3. The two most important reasons against vaccination were not being directly occupationally exposed (37.3\%) and doubting the effectiveness of the vaccine (37.3\%).

\section{Associations of demographic data, health status, occupational exposure and beliefs about influenza vaccination in the $2014 / 15$ season}

Table 4 presents the results of logistic regression of the factors associated with influenza vaccination. Age above 50 years $(\mathrm{OR}=3.73,95 \% \mathrm{CI}=1.27-10.97, p=0.017)$ and belief that the vaccine is effective in prevention of influenza $(\mathrm{OR}=12.38,95 \% \mathrm{CI}=4.06-38.30, p<0.001)$ were positively associated with influenza vaccination. Nurse occupation $(\mathrm{OR}=0.24, \quad 95 \% \mathrm{CI}=0.08-0.75, \quad p=0.014)$ was negatively associated with influenza vaccination in comparison to physicians. Included variables in the multiple logistic regression model explained $51.6 \%$ of the variance of the dependent variable (Nagelkerke $R^{2}=$ 0.516). Regarding multicollinearity the maximum VIF among explanatory variables was 1.57, which was 
Table 2 Reasons FOR influenza vaccination in the 2014/15 season

\begin{tabular}{lll}
\hline Reasons for vaccination & $n=30$ & $\%$ \\
\hline $\begin{array}{l}\text { As a health professional, I belong to the risk group } \\
\text { for infection }\end{array}$ & 25 & 83.3 \\
Self-protection against influenza & 21 & 70.0 \\
Protection of family members, co-workers & 18 & 60.0 \\
Protection of patients & 14 & 46.7 \\
My employer offers free vaccination against seasonal & 11 & 36.7 \\
influenza & & \\
Easy access to vaccine or vaccination & 11 & 36.7 \\
Age over 50 years & 8 & 26.7 \\
I have a chronic illness & 2 & 6.7 \\
\hline
\end{tabular}

substantially below the rule-of-thumb cutoff of 4 [18], so there were no issues with multicollinearity.

\section{Discussion}

In this study, a specific risk group - healthcare workers - were vaccinated only at $12 \%$. After several years of decline in the proportion of vaccinated inhabitants, only $3.3 \%$ of all Slovenian inhabitants were vaccinated in the season 2014/15, most in the age group over 65 years (11\%) where the percentage of vaccinated patients was similar to that of the group of health workers in the Koroška region [17]. The reasons behind the decision to vaccinate are known to be complex. In this study they were mostly connected with the psychological determinants, such as perceived risk of disease, past experience with the vaccine and attitudes toward vaccination and vaccine. Contextual factors - free and accessible vaccine -were mentioned, too. Nurses were more negatively oriented toward vaccination than physicians.

Our study showed a low vaccination rate of primary healthcare professionals. The studies from other countries show a wide range of vaccination coverage of health professionals [9-11]. American data indicate a 40\% rate of vaccination coverage of health professionals; their target is to reach $60 \%[19,20]$. Socan et al. showed that

Table 3 Reasons AGAINST influenza vaccination in the 2014/15 season

\begin{tabular}{lll}
\hline Reasons against vaccination & $n=220$ & $\%$ \\
\hline I do not belong to the influenza infection risk group & 83 & 37.7 \\
I have doubts in the effectiveness of the vaccine & 82 & 37.3 \\
Because of the adverse effects of the vaccine & 67 & 30.5 \\
Lack of time & 15 & 6.8 \\
I do not have sufficient information on the benefits & 8 & 3.6 \\
of the vaccination and the consequences of the disease & & \\
Financial reasons & 6 & 2.7 \\
I am allergic to one of the components of the vaccine & 4 & 1.8 \\
Poor vaccine availability & 0 & 0.0 \\
\hline
\end{tabular}

$41.7 \%$ of Slovenian physicians and dentists were vaccinated for seasonal and pandemic influenza in 2009/10 [12]. Among them, family physicians were vaccinated at $57.6 \%$, while only $27 \%$ were vaccinated in this study. If we consider all nurses (practice nurses, registered nurses, community nurses and nurse carers) only 12 out of 129 (9\%) were vaccinated, and if we include paramedics, who are registered nurses by their education but work in the emergency services and not in the family medicine team, it lowers to $8 \%$. This could be another reflection of a well-known negative trend in vaccination coverage among the population in the last years [17].

The highest percentage of vaccinated health professionals in 2014/15 were those employed by private contractors (the team represents one physician and one practice nurse) (23.8\%) and healthcare centres (18.5\%), while the vaccination coverage was extremely low amongst employees of nursing homes $(2.5 \%)$ and nil at the regional Healthcare emergency centre $(0 \%)$. We were particularly surprised by the low vaccination coverage of nursing home health professionals, since their clients are highly endangered. It was much lower than the vaccination rate found in other studies in nursing homes [21]. We explain these results with the fact that the largest share of health workers in nursing homes are nurses and the vaccination coverage in this professional group is found to be low. Additionally, according to 2008 data, only $69 \%$ of nursing home residents were vaccinated, i.e. a third of them were not vaccinated and therefore were exposed to infection [22].

\section{Factors associated with the decision to vaccinate}

In comparison to studies in other countries [9-11, 23, 24] where the most frequent reasons for vaccination were self-protection and free and easy access to vaccines, this study showed similar findings. The greatest motivator for vaccination of health professionals was the awareness that they are in the risk group for infection (83\% of vaccinated respondents reported it). It was followed by the tendency for self-protection (70\%), which was statistically not significantly behind, as it is essentially very similar and the protection of family members and co-workers (60\%). Despite the fact that vaccination of health professionals is highly recommended, also for the indirect protection of patients, this was clearly a lesser factor (46.7\%) in their choice to vaccinate.

In the bivariate analysis of factors associated with vaccination, the presence of a chronic illness, older age, being informed about influenza, belief in vaccine effectiveness and free vaccinations for employees were all significant, partly similar to Sočan et al., who showed that the factors associated with the decision to vaccinate are older age, being a hospital employee, being a vaccinator and having a chronic illness [12]. 
Table 4 Associations of demographic data, health status, occupational exposure and beliefs about vaccination to influenza vaccination in the 2014/15 season

\begin{tabular}{|c|c|c|c|c|c|c|}
\hline & $\begin{array}{l}\text { Without } \\
n=220(\%)\end{array}$ & $\begin{array}{l}\text { Vaccinated } \\
n=30(\%)\end{array}$ & cOR (95\% Cl) & $p$ & $\mathrm{aOR}(95 \% \mathrm{Cl})$ & P \\
\hline \multicolumn{7}{|l|}{ Sex } \\
\hline Male & $54(24.5)$ & $8(26.7)$ & 1.00 (basis) & & 1.00 (basis) & \\
\hline Female & $166(75.5)$ & $22(73.3)$ & $0.90(0.38-2.13)$ & 0.801 & $0.60(0.17-2.13)$ & 0.431 \\
\hline Age above 50 years & $49(22.3)$ & $17(56.7)$ & $4.56(2.07-10.04)$ & $<0.001$ & $3.73(1.27-10.97)$ & 0.017 \\
\hline \multicolumn{7}{|l|}{ Occupation } \\
\hline Physicians & $31(14.1)$ & $13(43.3)$ & 1.00 (basis) & & 1.00 (basis) & \\
\hline Nurses & $117(53.2)$ & $12(40.0)$ & $0.25(0.10-0.59)$ & 0.002 & $0.24(0.08-0.75)$ & 0.014 \\
\hline Paramedics & $17(7.7)$ & $0(0.0)$ & $0.65(0.35-1.61)$ & 0.413 & $0.36(0.08-1.65)$ & 0.332 \\
\hline Dentists & $10(4.5)$ & $4(13.3)$ & $0.95(0.25-3.60)$ & 0.944 & $2.28(0.28-18.54)$ & 0.442 \\
\hline Other health professionals & $45(20.5)$ & $1(3.3)$ & $0.53(0.01-0.43)$ & 0.006 & $0.20(0.02-2.04)$ & 0.175 \\
\hline \multicolumn{7}{|l|}{ Presence of chronic illness } \\
\hline no & $196(89.1)$ & $22(73.3)$ & 1.00 (basis) & & 1.00 (basis) & \\
\hline yes & $24(10.9)$ & $8(26.7)$ & $2.97(1.19-7.40)$ & 0.020 & $2.74(0.68-10.99)$ & 0.154 \\
\hline \multicolumn{7}{|c|}{ Institution offers free vaccination } \\
\hline no & $95(43.2)$ & $4(13.3)$ & 1.00 (basis) & & 1.00 (basis) & \\
\hline yes & $125(56.8)$ & $26(86.7)$ & $4.94(1.67-14.63)$ & 0.004 & $2.29(0.62-8.56)$ & 0.216 \\
\hline \multicolumn{7}{|c|}{ Well informed of the nature of the disease } \\
\hline no & $67(30.5)$ & $3(10.0)$ & 1.00 (basis) & & 1.00 (basis) & \\
\hline yes & $153(69.5)$ & $27(90.0)$ & $3.94(1.16-13.44)$ & 0.028 & $2.36(0.48-11.73)$ & 0.293 \\
\hline \multicolumn{7}{|c|}{ Vaccination is effective in prevention of influenza } \\
\hline not agree & $155(70.5)$ & $5(16.7)$ & 1.00 (basis) & & 1.00 (basis) & \\
\hline agree & $65(29.5)$ & $25(83.3)$ & $11.92(4.37-32.51)$ & $<0.001$ & $12.38(4.06-38.30)$ & $<0.001$ \\
\hline \multicolumn{7}{|l|}{ The vaccine is safe } \\
\hline not agree & $130(59.1)$ & $6(20.0)$ & 1.00 (basis) & & 1.00 (basis) & \\
\hline agree & $90(40.9)$ & $24(80.0)$ & $5.78(2.27-14.70)$ & $<0.001$ & $1.99(0.38-10.37)$ & 0.528 \\
\hline \multicolumn{7}{|l|}{ Exposure at the workplace } \\
\hline no & $45(20.5)$ & $3(10.0)$ & 1.00 (basis) & & 1.00 (basis) & \\
\hline yes & $175(79.5)$ & $27(90.0)$ & $2.31(0.67-7.97)$ & 0.184 & $2.27(0.43-11.92)$ & 0.332 \\
\hline
\end{tabular}

COR crude odds ratio, $95 \% \mathrm{Cl} 95 \%$ confidence interval, $a \mathrm{O}$ adjusted odds ratio by all included variables in the multivariable model (Nagelkerke $\left.\mathrm{R}^{2}=0.516\right)$

The multiple logistic regression model showed that the decision to vaccinate is influenced by age above 50 years, similar to other studies [25] and the respondents' belief that the vaccination is effective. Interestingly, in our model, trust in professional recommendations and public health or lack of professional information to vaccinate was not important to our participants, although they were important factors for vaccination in the systematic review of Prematunge [26].

\section{Factors influencing the decision not to vaccinate against influenza}

So-called hesitancy to vaccination [27] has been in the centre of research interest in the last years. This study shows that in the 2014/15 season, 220 health professionals $(88.0 \%)$ were not vaccinated. The most common reasons against vaccination were listed in two groups: health professionals do not feel the need for vaccination (37.7\%) and have a negative attitude toward vaccination, either from a first-hand bad experience $(30.5 \%)$ or doubt in the vaccination's effectiveness (37.3). Similar results were reported by foreign studies [9-11, 20]. This specific influenza hesitancy needs special investigation for further explanation. In the Schmid systematic review, lack of confidence in vaccine and vaccination was found to be the most important barrier for healthcare professionals [27].

Lack of information or insufficient awareness was mentioned by other studies as one of the most important reasons for refusing vaccination [9-11]. According to the respondents of this study, this did not impact the decision to vaccinate, as only $3.6 \%$ of health 
professionals mentioned it and statistically, it was significantly lagging behind the two primary reasons. In expert debates on mandatory vaccination for health professionals, however, it was emphasized that the decision depends on scientific evidence proving the effectiveness of the vaccine, its benefits, and its burdens and risks [28].

In this study, another important factor associated with the refusal to vaccinate turned out to be the respondents' occupation. The multiple logistic regression model showed a negative association with the profession of nurse. Our study does not present an answer explaining the causes. In the literature, however, we found studies that specifically investigate answers to this issue. In Switzerland, a qualitative study was conducted among nurses from two different hospitals. The interviews showed that they value and maintain a healthy life-style. They do not believe that influenza vaccinations are beneficial; on the contrary, they consider them to be harmful (falling ill post-vaccination). They are afraid of the side effects and they have doubts in the vaccine's effectiveness. Amongst their reasons not to vaccinate was also the wish for autonomous decision-making about one's body and health, and distrust in the environment and scientific study findings [29].

\section{Limitations of the study}

All primary health professionals of the Koroška region were invited to participate in the study, but we could only include the institutions and private contractors that agreed to participate. Hence, the sample was not representative. This affects the generalizability of the results although the response rate among the participants was good (74.8\%). The limitation of the study was also the fact that it focused on a single region in Slovenia, which is why the subgroups of health professionals were small and the generalization of the results for the entire population of health professionals in Slovenia is not possible. It was also not possible to analyse motivators and barriers according to the specific professional groups or to find any differences among them. Further on, the cross sectional design of the study did not allow any causal relationship to be established between the variables. Finally, as to our knowledge there are no validated questionnaires on this topic, the questionnaire we used was designed according to the literature review, aims of the study and previous qualitative data which limits the comparison of factors associated with influenza vaccination to other studies.

\section{Conclusions}

The downward trend of influenza vaccination amongst health professionals continued in 2014/15. The reasons for low vaccination in health professional group are complex. Health professionals need to be more aware that it is their professional duty to protect patients against influenza infection spread by healthcare workers. This is especially important for some professional groups, while physicians and dentists seem to be aware of it.

The vaccination of health workers is especially important for the protection of the patients in nursing homes. Further research to prove this effect and qualitative type research should be performed with some health professional groups, such as nurses, to get an insight in any specific aspects and possibilities for the improvement of influenza vaccination coverage.

\section{Abbreviations}

NIJZ: National Institute of Public Health; WHO: World Health Organization

Acknowledgements

We thank all healthcare workers who participated in the study.

Funding

The study was partly funded by the Slovenian Institute for the development of Family medicine. The funding institution had no role in the design, data collection, analysis, interpretation and writing of the manuscript.

Availability of data and materials

The datasets analysed during the current study are available from the corresponding author on reasonable request.

\section{Authors' contributions \\ KKJ developed the protocol of the study, gathered, analysed and interpreted the data. DP supervised the study, developed the protocol of the study, cooperated in the analysis and interpretation of the results and drafted the manuscript. Both authors read and approved the final version of the manuscript.}

\section{Ethics approval and consent to participate}

The study was approved by the Republic of Slovenia National Medical Ethics Committee at the Ministry of Health, No. 59/03/15. A permission to conduct the study at each of the health centres was obtained from the directors of the institutions. All participants signed informed consent form about voluntary participation in the study.

\section{Consent for publication}

Not applicable

\section{Competing interests}

The authors declare that they have no competing interests.

\section{Publisher's Note}

Springer Nature remains neutral with regard to jurisdictional claims in published maps and institutional affiliations.

\section{Author details}

'Department of Family Medicine, Faculty of Medicine, University of Ljubljana, Poljanski nasip 58, 1000 Ljubljana, Slovenia. ${ }^{2}$ Primary Health Care Centre Slovenj Gradec, Partizanska pot 16, 2380 Slovenj Gradec, Slovenia.

Received: 19 May 2018 Accepted: 29 October 2018

Published online: 14 November 2018

\section{References}

1. Factsheet about seasonal influenza. 2017. https://ecdc.europa.eu/en/ seasonal-influenza/facts/factsheet. Accessed 05 Nov 2017.

2. Influenza - Public Health - European Commission. 2017. https://ec.europa. eu/health/vaccination/influenza_en. Accessed 05 Nov 2017.

3. Kuster SP, Shah PS, Coleman BL, Lam P, Tong A, Wormsbecker B, et al. Incidence of influenza in healthy adults and health professionals: a 
systematic review and meta-analysis. PLoS One. 2011;6:e26239. https://doi. org/10.1371/journal.pone.0026239.

4. Dolan GP, Harris RC, Clarkson M, Sokal R, Morgan G, Mukaigawara M, et al. Vaccination of health care workers to protect patients at increased risk for acute respiratory disease: summary of a systematic review. Influenza Other Respir Viruses. 2013;(Suppl 2):93-6. https://doi.org/10.1111/irv.12087.

5. Maltezou HC, Poland GA. Vaccination policies for health care workers in Europe. Vaccine. 2014;32:4876-80.

6. Thomas RE, Jefferson T, Lasserson TJ. Influenza vaccination for health professionals who care for people aged 60 or older living in long-term care institutions. Cochrane Database Syst Rev. 2016;6:CD005187. https://doi.org/ 10.1002/14651858.CD005187.

7. Hayward AC, Harling R, Wetten S, Johnson AM, Munro S, Smedley J, et al. Effectiveness of an influenza vaccine programme for care home staff to prevent death, morbidity, and health service use among residents: cluster randomised controlled trial. BMJ. 2006;333:1241. https://doi.org/10.1136/bmj. 39010.581354 .55

8. Ranfl M, Kraigher A, Grgič Vitek M, Učakar M. Vaccination of healthcare workers: policies and practices, eNBOZ-Elektronske novice s področja nalezljivih bolezni in okoljskega varstva: Nacionalni inštitut za javno zdravje (NIJZ); 2015. p. 7. http://www.nijz.si/sites/www.nijz.si/files/uploaded/enboz_ avgust_2015.pdf. Accessed 23 Jul 2016

9. Hollmeyer HG, Hayden F, Poland G, Buchholz U. Influenza vaccination of health care workers in hospitals-a review of studies on attitudes and predictors. Vaccine. 2009;27:3935-44. https://doi.org/10.1016/j.vaccine.2009. 03.056.

10. Hofmann F, Ferracin C, Marsh G, Dumas R. Influenza vaccination of health professionals: a literature review of attitudes and beliefs. Infection. 2006;34: 142-7. https://doi.org/10.1007/s15010-006-5109-5.

11. Abu-Gharbieh E, Fahmy S, Rasool BA, Khan S. Influenza Vaccination: Healthcare workers attitude in three Middle East countries. Int J Med Sci. 2010;7:319-25

12. Sočan M, Erčulj V, Lajovic J. Knowledge and attitudes on pandemic and seasonal influenza vaccination among Slovenian physicians and dentists. Eur J Pub Health. 2013;23:92-7. https://doi.org/10.1093/eurpub/cks006.

13. EUR-Lex Access to European Union law. (n.d.). http://eur-lex.europa.eu/legalcontent/EN-SL/TXT/?uri=CELEX\%3A32000L0054\&from=EN. Accessed 05 Nov 2017

14. Directive 2000/54/EC. Biological agents at work of the European Parliament and of the Council of 18 September 2000 on the protection of workers from risks related to exposure to biological agents at work (seventh individual directive within the meaning of Article 16(1) of Directive 89/391/ EEC). Off J L. 2000;262(43):21-45 https://eur-lex.europa.eu/legal-content/EN/ TXT/?uri=CELEX:32000L0054. Accessed 23 July 2016.

15. Nowalk MP, Lin CJ, Raymund M, Bialor J, Zimmerman RK. Impact of hospital policies on health care workers' influenza vaccination rates. Am J Infect Control. 2013;41:697-701. https://doi.org/10.1016/j.ajic.2012.11.011.

16. National Institute of Public Health (NIJZ). Data Portal https://podatki.nijz.si/ Selection.aspx?px_tableid=BPI_TB01.px\&px_path= NIJZ\%20podatkovni\%20portal_5\%20Viri\%20v\%20zdravstvu_ 1\%20lzvajalci\%20zdravstvene\%20dejavnosti\&px_language=en\&px_db= NIJZ\%20podatkovni\%20portal\&rxid=9bb6b38c-fb1e-474f-94ac-2a3dce77adf6. Accessed 07 Oct 2017.

17. Učakar V, Jeraj I, Grgič Vitek M, Kraigher A. Analiza izvajanja cepljenja v Sloveniji v letu 2013: Nacionalni Inštitut za javno zdravje, Center za nalezljive bolezni; 2015. p. 33-40. http://www.nijz.si/files/uploaded/porocilo_ cepljenje_2013.pdf. Accessed 02 Nov 2017

18. O'Brien RM. A caution regarding rules of thumb for variance inflation factors. Qual Quant. 2007:41:673-90.

19. Pearson ML, Bridges CB, Harper SA. Influenza vaccination of health-care personnel: recommendations of the healthcare infection control practices advisory committee (HICPAC) and the advisory committee on immunization practices (ACIP). MMWR Recomm Rep. 2006;55:1-16.

20. Ajenjo MC, Woeltje KF, Babcock HM, Gemeinhart N, Jones M, Fraser V. Influenza vaccination among health professionals: ten-year experience of a large healthcare organization. Infect Control Hosp Epidemiol. 2010;31:23340. https://doi.org/10.1086/650449.

21. Shroufi A, Copping J, Musonda P, Vivancos R, Langden V, Armstrong S, Slack R. Influenza vaccine uptake among staff in care homes in Nottinghamshire: a random cluster sample survey. Public Health. 2009;123:645-9. https://doi. org/10.1016/j.puhe.2009.09.014.
22. Petek Šter M. Cepljenje proti gripi in pnevmokoku pri starostnikih v domovih starejših občanov. Influenza and pneumoccocal vaccination of elderly nursing home residents. Zdravstveno varstvo. 2008:47:117-25.

23. Collange F, Verger P, Launay O, Pulcini C. Knowledge, attitudes, beliefs and behaviors of general practitioners/family physicians toward their own vaccination: a systematic review. Human Vacc Immunother. 2009;3(12): 1282-92. https://doi.org/10.1080/21645515.2015.1138024.

24. Grdadolnik U, Socan M. The impact of socio-economic determinants on the vaccination rates with rotavirus and human Papiloma virus vaccine. Zdravstveno Varstvo. 2015;16(55):43-52. https://doi.org/10.1515/sjph-2016-0007.

25. Mytton OT, O'Moore EM, Sparkes T, Baxi R, Abid M. Knowledge, attitudes and beliefs of health care workers towards influenza vaccination. Occup Med. 2013;63:189-95. https://doi.org/10.1093/occmed/kat002.

26. Prematunge C, Corace K, McCarthy A, Nair RC, Pugsley R, Garber G. Factors influencing pandemic influenza vaccination of healthcare workers-a systematic review. Vaccine. 2012;30:4733-43. https://doi.org/10.1016/j. vaccine.2012.05.018

27. Schmid P, Rauber D, Betsch C, Lidolt G, Denker ML. Barriers of influenza vaccination intention and behavior - a systematic review of influenza vaccine hesitancy, 2005 - 2016. PLoS One. 2017;12:e0170550. https://doi.org/ 10.1371/journal.pone.0170550.

28. Wicker S, Marckmann G. Vaccination of health care workers against influenza: is it time to think about a mandatory policy in Europe? Vaccine. 2014:32:4844-8. https://doi.org/10.1016/j.vaccine.2013.09.062.

29. Pless A, McLennan SR, Nicca D, Shaw DM, Elger BS. Reasons why nurses decline influenza vaccination: a qualitative study. BMC Nurs. 2017:16:20. https://doi.org/10.1186/s12912-017-0215-5.

\section{Ready to submit your research? Choose BMC and benefit from:}

- fast, convenient online submission

- thorough peer review by experienced researchers in your field

- rapid publication on acceptance

- support for research data, including large and complex data types

- gold Open Access which fosters wider collaboration and increased citations

- maximum visibility for your research: over $100 \mathrm{M}$ website views per year

At $\mathrm{BMC}$, research is always in progress.

Learn more biomedcentral.com/submissions 